\title{
PENGARUH PREVENTIVE MAINTENANCE UNIT PUMPING MF420EX TERHADAP HASIL PRODUKSI DI PT. KALIMANTAN PRIMA PERSADA
}

\author{
${\text { Budi Irawan', Idzani Muttaqin }{ }^{1} \text {, Yassyir Maulana }}^{1}$ \\ Program Studi Teknik Industri, Fakultas Teknik \\ Universitas Islam Kalimantan Muhammad Arsyad Al Banjari Banjarmasin \\ Jl. Adhyaksa No 2 Kayu Tangi Banjarmasin 70123 Indonesia \\ e-mail : budiirawan794@gmail.com
}

\begin{abstract}
Abstrak-Preventive Maintenance merupakan perawatan yang dilakukan terjadwal, umumnya secara periodik, di mana sejumlah tugas pemeliharaan seperti inspeksi, perbaikan, penggantian, pembersihan, pelumasan dan penyesuaian dilaksanakan. Tujuan penelitian ini yaitu untuk mengetahui seberapa banyak pengaruh dari kegiatan Preventive Maintenance unit pumping MF420EX terhadap hasil produksi. Metode penelitian yang digunakan dalam penelitian ini yaitu jenis penelitian survei, dan metode fishbone. Pada penelitian ini peneliti mencoba menganalisis pengaruh Preventive Maintenance unit pumping MF420EX terhadap hasil produksi di PT. Kalimantan Prima Persada sehingga diharapkan mampu memberikan saran perbaikan untuk kegiatan preventive maintenance yang akan datang. Data yang digunakan dalam peneltian ini adalah data-data preventive maintenance dari bulan agustus tahun 2020 sampai dengan bulan desember tahun 2020. Hasil penelitian menunjukan ada pengaruh preventive maintenance terhadap hasil produksi, PA 92,39\%, MTBS 216 jam, MTTR 1,83 jam, dan produksi 2.425.199 MT. Jadi dapat disimpulkan bahwa terdapat pengaruh preventive maintenance terhadap hasil produksi, akan tetapi tidak menutup kemungkinan ada faktor-faktor lain yang ikut mempengaruhi di dalamnya yang masih belum diteliti.
\end{abstract}

Kata Kunci : Preventive Maintenance, metode fishbone, PA, MTBS, MTTR.

\section{PENDAHULUAN}

$D$ erkembangan kemajuan di dunia industri pertambangan saat ini terus mengalami kemajuan,salah satunya pada perusahaan PT. Kalimantan Prima Persada anak perusahaan dari ASTRA group, sebagai perusahaan pertambangan dengan visi menjadi perusahaan pertambangan terbesar di indonesia dengan bisnis prosesnya yaitu mining service, hauling service, dan port service. Dalam hal ini tentu sebuah industri pertambangan melakukan proses produksi dengan bantuan alat-alat teknologi modern, di antaranya: heavy dump truck, excavator, dozer, genset, light truck, light dump, dan pumping MF420EX, dalam membantu proses produksi.

Proses produksi pada perusahaan ini berlangsung secara terus menerus, sehingga perlu diimbangi dengan proses perawatan dan perbaikan mesin agar selama proses produksi alat tidak mengalami kegagalan fungsi yang menyebabkan proses produksi terhenti. Tentu dalam hal ini akan sangat merugikan sekali bagi perusahaan.

Salah satu usaha penanganan masalah tersebut yaitu dengan jalan menerapkan kegiatan perawatan dan perbaikan terhadap alat-alat produksi. Ada beberapa sistem perawatan yang digunakan oleh perusahaanperusahaan besar pada umumnya. Dalam hal ini penulis mengerucutkan pada jenis sistem preventive maintenance yang dapat di gunakan perusahaan.

Preventive maintenance menurut pendapat Ebelling (997:189) dalam Edi Santoso \& Edwin Julianto C. adalah perawatan yang dilakukan terjadwal umumnya secara periodik, di mana sejumlah tugas pemeliharaan seperti inspeksi, perbaikan, penggantian, pembersihan, pelumasan dan penyesuaian dilaksanakan. Keuntungan menggunakan sistem preventive maintenance adalah dapat mencegah adanya kerusakan pada alat-alat yang digunakan, meminimalkan biaya perbaikan, keselamatan kerja lebih terjamin, tidak banyak membutuhkan peralatan atau mesin pengganti, selain itu preventive maintenance dapat memperpanjang umur mesin serta mengurangi kerusakan yang dapat terjadi sewaktu-waktu selama proses produksi (Sumantri, 1989:74).

Sehingga dengan sistem preventive maintenance ini diharapkan mampu memberikan solusi yang efektif bagi penanganan alat-alat produksi agar tetap bekerja secara maksimal dan tidak mengalami kegagalan fungsi yang menyebabkan terget produksi tidak tercapai. Berdasarkan latar belakang diatas penulis mencoba meneliti tentang seberapa banyak pengaruh preventive maintenance pada unit pumping MF420EX terhadap hasil produksi agar tetap sesuai dengan target yang ditentukan. Serta langkahlangkah preventive maintenance yang dapat dilakukan untuk menunjang hasil produksi tersebut.

\section{METODE PENELITIAN}

Pada bab metodologi penelitian ini menjelaskan tentang tahap-tahap yang akan dilakukan dari awal hingga akhir yang digunakan dalam proses penelitian. Adapun langkah-langkah tersebut akan dijelaskan dibawah ini.Adapun beberapa teknik yang diambil oleh penulis yaitu :

1) wawancara atau mengadakan komunikasi langsung dengan kepala bagian produksi tentang hal-hal yang berhubungan dengan obyek yang diteliti atau dengan karyawan yang terlibat langsung didalam perusahaan 
2) tersebut dengan menanyakan hal-hal yang berhubungan poses produksi, data kerusakan bulanan pada mesin produksi.

3) Dokumentasi data yang diperoleh dengan mempelajari dokumen-dokumen perusahaan yang berhubungan dengan permasalahan dalam penelitian ini. Data yang diperoleh berhubungan dengan data kerusakan setiap bulan pada mesin produksidan lain-lain.

Berdasarkan data-data yang diperoleh dari perusahaan, selanjutnya penulis melakukan pengolahan data dan perhitungan untuk menunjang penelitian tersebut. Pengolahan data yang dilakukan sebagai berikut:

1) Data Fishbone

2) Perhitungan Physical Availability ( PA)

3) Perhitungan Mean Time Between Shutdown (MTBS)

4) Perhitungan Mean Time to Repair (MTTR)

\section{HASIL DAN PEMBAHASAN}

Pada bab ini menjelaskan tentang pengumpulan data dan pengolahan data.dilakukan pengumpulan data yang kemudian dilakukan pengolahan data. Tahap pengolahan data dilakukan dengan pendekatan Preventive Maintenance. Lamanya periode yang diambil untuk penelitianyang dimulai pada bulan Agustus 2020 sampai dengan Desember 2020 yang digunakan sebagai acuan untuk menentukkan interval perawatan. Di perusahaan PT. Kalimantan Prima Persada yang berada di site rantau kal-sel memiliki 3 unit multiflo tipe MF 420EX dengan kode unit WP0074, WP0077, dan WP0087, dan jam kerja unit tersebut beropersi selama 24 jam dalam satu hari.

\section{MTBS (Mean Time Between Shuntdown)}

Diagram di bawah menunjukan hasil perhitungan perbandingan MTBS, di mana pada bulan Agustus sampai dengan bulan September proses preventive maintenance belum tepat,dan bulan Oktober sampai dengan bulan Desember sudah berjalan dengan baik.

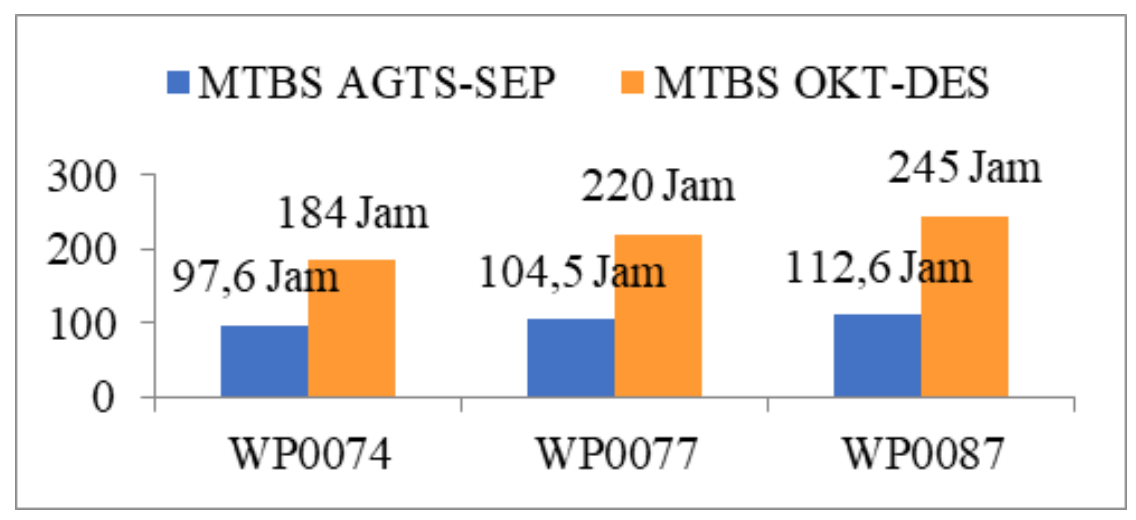

Gambar 1. Diagram MTBS (Mean Time Between Shutdown)

\section{MTTR (Mean Time to Repair)}

Diagram di bawah menunjukan hasil perhitungan perbandingan MTTR, di mana pada bulan Agustus sampai dengan bulan September proses preventive maintenance belum tepat, dan bulan Oktober sampai dengan bulan Desember sudah berjalan dengan baik.

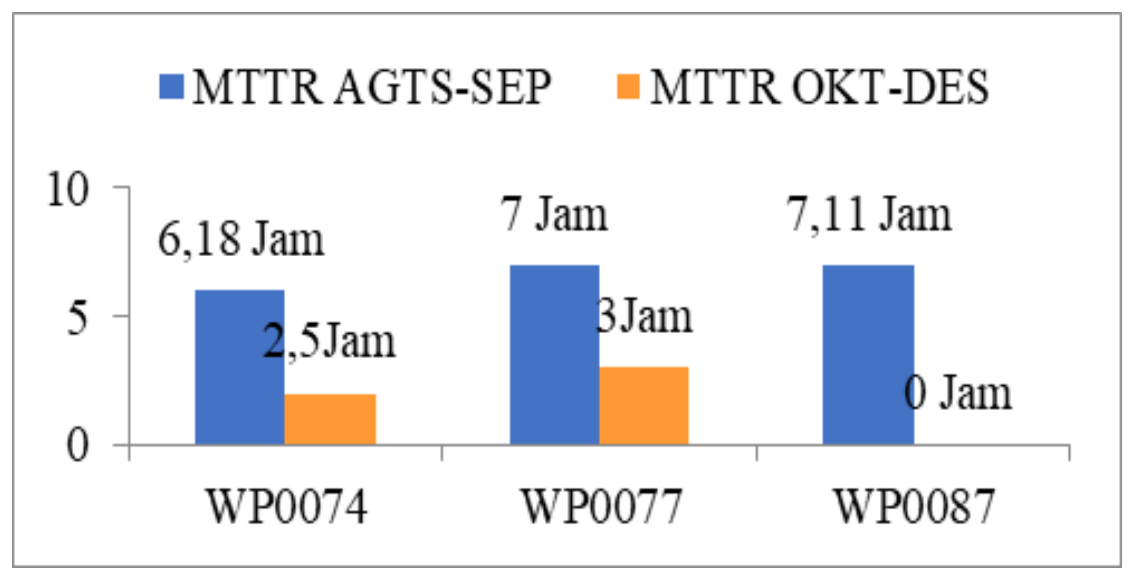

Gambar 2. Diagram MTTR (Mean Time To Repair)

Pengaruh Preventive Maintenance Unit Pumping MF420EX terhadap Hasil Produksi Di PT. Kalimantan Prima Persada 


\section{PA (Physical Availability)}

Diagram di bawah menunjukan hasil perhitungan perbandingan PA, di mana pada bulan Agustus sampai dengan bulan September proses preventive maintenance belum tepat, dan bulan Oktober sampai dengan bulan Desember sudah berjalan dengan baik.

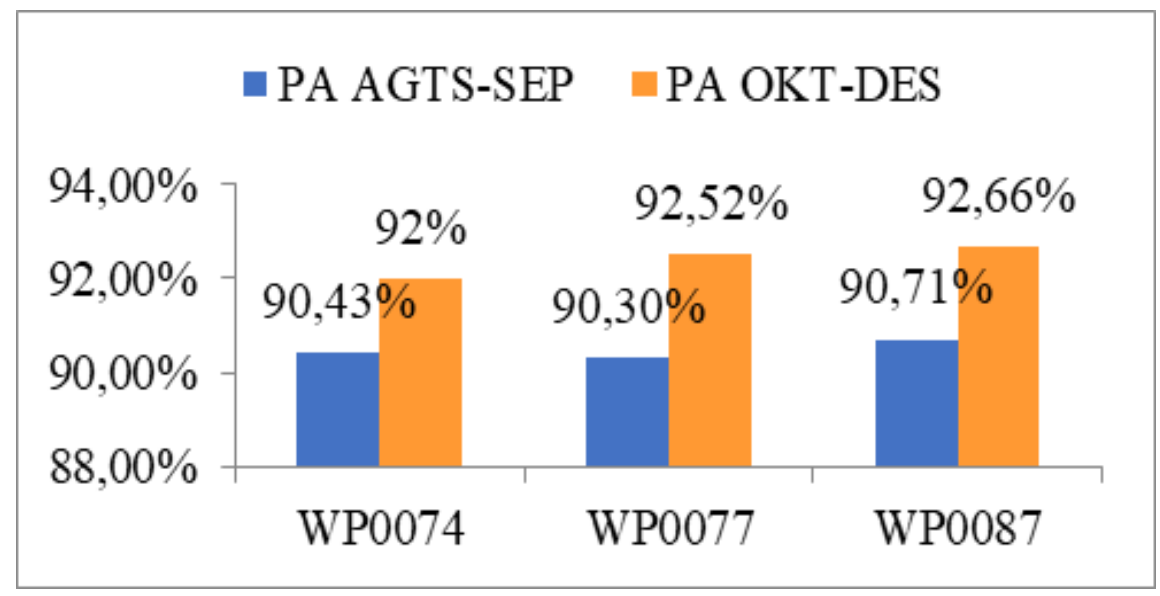

Gambar 3. Diagram PA (Physical Availability)

\section{UA (Utilization Of Availability)}

Perhitungan pencapaian produksi juga mengalami peningkatan dapat di lihat pada gambar di atas. Di mana pada bulan Oktober sampai dengan bulan Desember, hasil produksi mencapai 2.452.199 MT, dan proses preventive maintenance sudah berjalan dengan sangat baik.

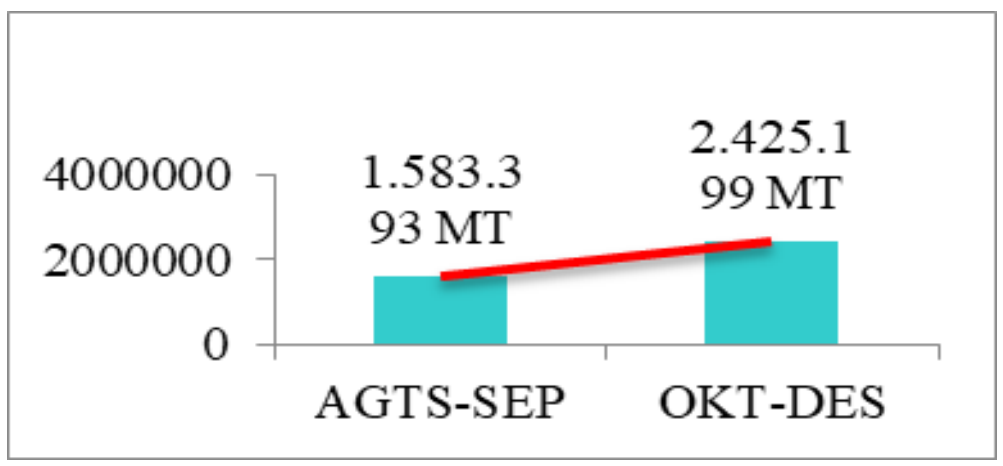

Gambar 4. Diagram UA (Utilization Of Availability)

\section{KESIMPULAN DAN SARAN}

\section{Kesimpulan}

Pada bab ini penulis memberikan penjelasan tentang kesimpulan dan saran dari hasil perhitungan interval waktu preventive maintenance. Berikut penjelasannya. Metode yang di gunakan oleh pihak plant untuk memperbaiki sistem preventive maintenance yaitu dengan menggunakan metode fishbone. Hasil yang di dapat seringnya terjadi kerusakan yang tidak terjadwal pada unit pompa adalah maintenance belum dilakukan sesuai dengan OMM multiflo, sudah ada jadwal maintenance yang terjadwal tetapi belum tepat, dan mekanik sudah mengerti prosedur maintenance tetapi belum sesuai OMM multiflo dikarenakan mekanik belum mendapatkan training khusus multiflo.
Hasil perhitungan pada bulan Agustus sampai dengan bulan September sebelum dilakukan preventive mainteanance yang tepat yaitu PA 90,48 \%, MTBS 104,9 jam, MTTR 6,76 jam, dan produksi 1.583.393 MT.Hasil yang di dapat belum mencapai target yang di inginkan. PT. Kalimantan Prima Persada terus melakukan perbaikan-perbaikan dan improvement agar target yang di inginkan dapat tercapai. Pada bulan Oktober sampai dengan bulan Desember setelah melakukan preventive maintenance yang tepat PT. Kalimantan Prima Persada dapat mencapai hasil yang baik dengan PA 92,39\%, MTBS 216 jam, MTTR 1,83 jam, dan produksi 2.425.199 MT.

\section{Saran}

Ada beberapa saran yang diberikan kepada perusahaan adalah : 
1) Pihak perusahaan di harapkan terus melakukan improvement-improvement, agar mendapatkan hasil yang selalu memuaskan.

2) Perusahaan di harapkan konsisten dalam melakukan preventive maintenance yang sudah di jadwalkan dan

\section{DAFTAR PUSTAKA}

[1] Dawei, Li. Zhang Zhihua. Zhong Qianghui. Zhai Yali. 2014. Chinese Society Aeronautics and Astronautics \& Beihang University, Chinese Journal Aeronatics, 27(4): 821-828. Abstrak tentang Performance deteriorationmodeling and optimal preventive maintenance strategy under scheduled servicing subject to mission time.

[2] Mahaji Puteri, Renty Anugerah. 2014. Jurnal Fakultas Teknik Universitas Muhammadiyah Jakarta, ISSN 2407-1846, 12 Nopember 2014, AnalisisPengaruh Nilai Availability Dan Waktu Downtime Terhadap Produktivitas Mesin Pada selalu mengikuti prosedur yang sudah di sepakati bersama, memberikan training knowledge pada mekanik agar pengetahuan mekanik terus bertambah.

3) Selalu mengutamakan keselamatan di setiap pekerjaan.

[3] Automatic Ampoule Filling Dan Sealing Machine Di Pt. Indofarma, Tbk.

[4] Santoso, Edi. Julianto Chairul, Edwin. 2007. Jurnal Inasea, Vol. 8134 No.2, Oktober 2007: 134-143, Minimasi Downtime Tool Punch Mesin HeadingPada Preventive Maintenance Dengan Metode Age Replacement. Jurusan Teknik Industri, Fakultas Teknik, Universitas Bina Nusantara.

[5] Sumantri, 1989. Perawatan Mesin. Jakarta: DIKTI P2LPTK

[6] PT. Kalimantan Prima Persada KMMS HandbookPlant Development. 2015.

[7] Modul KMMS Revisi 3. 